\title{
New-onset Atrial Fibrillation in Patients Presenting with Acute Myocardial Infarction
}

Zafar Iqbal $^{1}$, Muhammad Naeem Mengal ${ }^{2}$, Abida Badini ${ }^{3}$, Musa Karim ${ }^{4}$

1. Interventional Cardiology, National Institute of Cardiovascular Diseases, Karachi, PAK 2. Cardiology, National Institute of Cardiovascular Diseases, Karachi, PAK 3. Family Medicine, Aga Khan University, Karachi, PAK 4. Statistics, National Institute of Cardiovascular Diseases, Karachi, PAK

$\square$ Corresponding author: Musa Karim, mkarim.nicvd@gmail.com

Disclosures can be found in Additional Information at the end of the article

\section{Abstract}

\section{Background}

Atrial fibrillation (AF) can be seen secondary to the complications after acute myocardial infarction (AMI), but it has a poor prognosis when occurs independently. These patients are prone to an increased risk of all in-hospital major cardiac complications and also at an increased risk of mortality. Therefore, it is important to quantify the burden of this aggravating complication in an otherwise lethal manifestation of acute coronary syndrome. The aim of this study was to find the frequency of AF in patients presenting with AMI and the factors associated with it.

\section{Methods}

We conducted this observational study on 216 patients who presented with AMI at the largest cardiac center of Karachi, Pakistan from July 2014 to January 2015 with AMI without a past history of AF. Patients underwent routine clinical assessment and laboratory investigations. Atrial fibrillation, detected on electrocardiographic assessment at the time of admission or during hospital stay without a prior history of persistent atrial flutter or paroxysmal atrial fibrillation, was classified as new-onset atrial fibrillation (AF).

\section{Results}

We selected a total of 216 patients, 117 (54.2\%) male and mean age of $50.76 \pm 6.00$ years. Diabetes was found in 140 (64.8\%), 164 (75.9\%) were hypertensive, and 61 (28.2\%) patients were smokers. ST-segment elevation myocardial infarction (STEMI) was diagnosed in 97 (44.9\%) patients. The new onset of atrial fibrillation was found in 27 (12.5\%) of the patients

Received 03/27/2019 Review began 04/02/2019 Review ended 04/10/2019 Published 04/16/2019

\section{(c) Copyright 2019}

lqbal et al. This is an open access article distributed under the terms of the Creative Commons Attribution License CC-BY 3.0., which permits unrestricted use, distribution, and reproduction in any medium, provided the original author and source are credited. with AMI. Univariate analysis revealed a statistically significant association of new-onset AF with hypertension.

\section{Conclusion}

The new onset of atrial fibrillation was found in $12.5 \%$ of the patients presented with acute myocardial infarction. It is a significant complication in term of its frequency in AMI and it is more common in hypertensive patients.

Categories: Cardiology 
Keywords: atrial fibrillation, atrial flutter, myocardial infarction, new-onset

\section{Introduction}

Atrial fibrillation (AF) is an electrical complication, commonly observed in acute myocardial infarction (AMI) patients, with an incidence ranging from $6 \%$ to $19 \%$ [1]. However, most of these patients had pre-existing AF, the actual incidence of new-onset atrial fibrillation is as high as 5\% [2-3]. Various studies have confirmed its association with increased immediate-, long-, and short-term mortality and adverse events such as heart failure (HF) and cerebrovascular accident (CVA) [1,4-6]. Pathogenesis of new-onset AF in patients with AMI is acute left atrial dilatation due to increased atrial pressure caused by an underlying factor [7]. It can be seen secondary to the complications after AMI, but it has a poor prognosis when occurs independently [8].

In a clinical setting, early detection of the AF and introduction of protective medication and therapies might greatly help to contain the progression of arrhythmia from an easily manageable condition to a completely refractory condition [7]. However, with the 'silent' nature of arrhythmia, for most of the times, its early detection is difficult and a significant number of patients, around one third, did not even notice the so-called asymptomatic atrial fibrillation [7].

Clinically, AF is generally associated with various risk factors such as advanced age, HF, hypertension, valvular heart disease, obesity, cardiomyopathies and thyroid dysfunction [9-10]. AF leads to various clinically adverse conditions such as mortality, cerebrovascular accident, and other thromboembolic events including HF, left ventricular (LV) dysfunction, reduced exercise capacity and quality of life [11]. The risk of AF increases with an increase in age; a prevalence of $0.5 \%$ was reported at 40 to 50 years of age and $5 \%$ to $15 \%$ at 80 years of age [7].

Clinical management is challenging, for the cases with AMI complicated by AF, due to the lack of guidelines and data regarding embolic risks and bleeding and suitable antithrombotic treatment [12-13]. In a majority of the cases, AF is chronic in nature, while new-onset AF develops occasionally. There are substantial differences in the pathophysiological mechanisms, management, and clinical impact of both conditions [14-17]. A very limited data on new-onset AF in AMI is available for the Pakistani population. Therefore, it is important to quantify the burden of this aggravating complication in an otherwise lethal manifestation of acute coronary syndrome. The aim of this study was to find the frequency of AF in patients presenting with AMI and the factors associated with it.

\section{Materials And Methods}

This observational study was conducted at the largest cardiac center in Karachi, Pakistan from July 2014 to January 2015. We included 216 male and female patients between the ages of 20-60 years with a diagnosis of AMI, within four days of admission to the hospital. Exclusion criteria for the study were patients with a prior diagnosis of AF and patients having AF due to any other causes apart from AMI. Institutional ethical review committee (ERC) approval was taken (ERC39/2014) and informed consent was obtained by the researcher from all the patients. Assessment of AMI was made on the basis of history, ECG, and cardiac isoenzyme (troponin-I). AMI was classified as non-ST-segment elevation myocardial infarction (NSTEMI) and STsegment elevation myocardial infarction (STEMI). Patient demographics (gender and age) and clinical history regarding hypertension, diabetes, and smoking were obtained. Treatment and management of the diseases were planned as per the guidelines and opted management strategy, medical treatment, percutaneous coronary intervention (PCI), or streptokinase, were recorded. 
All the patients underwent continuous electrocardiography monitoring for detection of newonset AF. Electrocardiographic criteria for the presence of AF were P-waves absence, coarse or fine fibrillatory waves, and irregularity of the RR intervals. AF, detected on electrocardiographic assessment at the time of admission or during hospital stay without a prior history of persistent atrial flutter or paroxysmal atrial fibrillation, was classified as newonset AF. As per the AHA 2001 guidelines, an episode of AF with a minimal time of more than 30s was counted [10]. The final outcome was measured on the fourth day of admission. Frequencies and percentages were calculated for gender, diabetes mellitus, hypertension, smoking status, type of AMI, type of emergency treatment i.e. streptokinase (SK) and primary PCI, and new-onset AF. The mean and standard deviation were calculated for continuous variables such as age. Stratification was done on age, gender, comorbid including diabetes mellitus, hypertension, smoking status, type of AMI, type of treatment (medical management, SK, primary PCI). Chi-square test was applied, and statistical significance criteria were $p$-value $\leqslant 0.05$.

\section{Results}

We selected a total of 216 patients. There were 117 (54.2\%) male and 99 (45.8\%) female patients. The mean age was $50.76 \pm 6.00$ years. Diabetes was found in 140 (64.8\%), 164 (75.9\%) patients were with hypertension, and 61 (28.2\%) patients were smokers. Regarding diagnosis, 97 (44.9\%) patients presented with STEMI and 119 (55.1\%) got admitted with NTEMI. The demographics and clinical characteristics of patients are presented in Table 1. 


\section{Cureus}

\section{Frequency [n]}

Gender

Male

Female

Age Groups

$36-45$ years

$46-55$ years

More than 55 years

Comorbid

Diabetic

Hypertension

Smoking

Type of Acute Myocardial Infarction (AMI)

STEMI

NSTEMI

Treatment Type

Medical Treatment

$\mathrm{PCl}$

Streptokinase

\section{Percentage [\%]}

$45.8 \%$

$21.3 \%$

$53.2 \%$

$25.5 \%$

$64.8 \%$

$75.9 \%$

$5.6 \%$

$33.8 \%$

\section{TABLE 1: Demographic and clinical characteristics of the patients}

NSTEMI, non ST-segment elevation myocardial infarction; STEMI, ST-segment elevation myocardial infarction, PCI, percutaneous coronary intervention

According to statistical analysis, out of a total of 216 patients with AMI, new-onset AF was found in 27 (12.5\%). Univariate analysis revealed a statistically significant association of newonset $\mathrm{AF}$ with hypertension, while no significant association was found between age, gender, type of AMI and type of treatment given to the patient after AMI. New-onset AF by baseline characteristics of the patients is presented in Table 2.

\section{Base $[\mathrm{N}]$}

\section{New-onset atrial fibrillation}

Percentage (n) p-value ${ }^{* *}$

Gender 


\section{Cureus}

Male

117

Female

99

46

115

$46-55$ years

More than 55 years

55

Diabetes mellitus

Non-diabetic

76

140

Diabetic

Hypertension status

Non-hypertensive

52

164

Hypertensive

Smoking status

Non-smokers

155

Smokers

61

Type of Acute Myocardial Infarction (AMI)

$\begin{array}{ll}\text { STEMI } & 97\end{array}$

NSTEMI

119

Treatment given

Medical Treatment

$\mathrm{PCl}$

12

Streptokinase

73

Total
$12.8 \%(15)$

$12.1 \%(12)$

$10.9 \%(6)$

$15.8 \%(12)$

$10.7 \%(15)$

$0.002^{*}$

$16.5 \%(27)$

$15.5 \%(24)$

$4.9 \%(3)$

$0.035^{*}$

$15.5 \%(15)$

$10.1 \%(12)$

0.234

$11.5 \%(15)$

$25 \%(3)$

$12.3 \%(9)$

$12.5 \%(27)$

\section{TABLE 2: Frequency and association of new-onset of AF}

*Statistically significant at 0.05 level of significance; ${ }^{* *} p$-values are based on the chi-square test.

AF, atrial fibrillation; NSTEMI, non ST-segment elevation myocardial infarction; STEMI, ST-segment elevation myocardial infarction; $\mathrm{PCl}$, percutaneous coronary intervention

\section{Discussion}

AMI is one of the major health problems in both developed and developing or underdeveloped 
countries. Occurrence of AF in acute AMI setting is not an uncommon phenomenon; various studies have reported increased immediate-, short-, or long-term mortality, adverse events and other thromboembolic events including HF, LV dysfunction, reduced quality of life, and exercise capacity in AMI patients complicated by AF [1,4-6,11].

We conducted this study on patients admitted with the diagnosis of AMI and between 20 and 60 years of age. In our study, we found that $12.5 \%$ of patients admitted with the diagnosis of AMI developed new-onset AF; this is within the range of reported frequency in previous studies [2,4-9,13-18]. It has been observed in past studies that patients with AF have more risk factors and as a result more in-hospital complications. It is important to assess all these important confounding factors while studying the association between short- and long-term outcomes and new-onset AF [19].

The important findings of our study are AF is a common arrhythmia observed in $12.5 \%$ of the patients with AMI and patients with hypertension have more chances to develop AF. In epidemiological studies, about $10 \%$ to $16 \%$ of AMI patients have been noted to develop AF during the hospitalization and an increasing trend was observed in its prevalence over the years [20]. In a study performed by Rathore et al., AF was reported in about $22 \%$ of patients during hospitalization in the elderly population of $>65$ years [7]. In AMI, paroxysmal AF has been reported in about $10 \%$ of the patients when thrombolytics were not in clinical practice and in about $9 \%$ of patients after the use of thrombolytics [21]. In the DIAMOND-AMI study, for the placebo group (without dofetilide), AF developed in two percent of the patients during the first year of AMI [22].

In TRACE study, the group of patients in which angiotensin-converting enzyme inhibitors (ACE-I) trandolapril was not given, the placebo subgroup, 5.3\% developed new-onset atrial fibrillation [23]. Past studies have shown that the risk of stroke, left ventricular dysfunction, and death associated with new-onset AF are increased. It has been demonstrated in a number of studies that new-onset AF is an independent predictor of not only in-hospital but also shortand long-term mortality [1,4-6,8,11]. In agreement with previous studies, we found that patients with new-onset AF were with worse baseline characteristics and that hypertension was the significant predictor of AF in these patients.

The current study has several limitations; due to the observational nature of the study, we are unable to establish causality for new-onset AF, treatment, and outcomes. Second, as all the patients were on ACE-I or ARBs, this may have altered the frequency of new-onset AF. It is suggested that more prospective and interventional studies need to be conducted, with larger sample size to find the impact and association of complication of AF in the context of AMI, to possibly prevent or manage such patient more effectively.

\section{Conclusions}

In our study, new-onset AF was found in $12.5 \%$ of patients with AMI and most of them were hypertensive and elders. The majority of patients who developed new-onset AF after AMI had HF. In the thrombolytic era, AF remained a common and important complication of AMI. It is also suggested that these patients be managed timely with close clinical monitoring, anticoagulation, and treating AF accordingly considering AMI whenever possible.

\section{Additional Information \\ Disclosures}

Human subjects: Consent was obtained by all participants in this study. National Institute of Cardiovascular Diseases Karachi issued approval ERC-39/2014. Approval was taken from the 
ethical review committee of the National Institute of Cardiovascular Diseases Karachi, approval \#:ERC-39/2014. Animal subjects: All authors have confirmed that this study did not involve animal subjects or tissue. Conflicts of interest: In compliance with the ICMJE uniform disclosure form, all authors declare the following: Payment/services info: All authors have declared that no financial support was received from any organization for the submitted work.

Financial relationships: All authors have declared that they have no financial relationships at present or within the previous three years with any organizations that might have an interest in the submitted work. Other relationships: All authors have declared that there are no other relationships or activities that could appear to have influenced the submitted work.

\section{References}

1. Bahouth F, Mutlak D, Furman M, et al.: Relationship of functional mitral regurgitation to new-onset atrial fibrillation in acute myocardial infarction. Heart. 2010, 96:683-8.

10.1136/hrt.2009.183822

2. Parashar S, Kella D, Reid KJ, et al.: New-onset atrial fibrillation after acute myocardial infarction and its relation to admission biomarkers (from the TRIUMPH registry). Am J Cardiol. 2013, 112:1390-5. 10.1016/j.amjcard.2013.07.006

3. Löfmark R, Orinius E: Supraventricular tachyarrhythmias in acute myocardial infarction. Acta Med Scand. 1978, 203:517-20. 10.1111/j.0954-6820.1978.tb14918.x

4. Kundu A, O'Day K, Shaikh AY, et al.: Relation of atrial fibrillation in acute myocardial infarction to in-hospital complications and early hospital readmission. Am J Cardiol. 2016, 117:1213-8. 10.1016/j.amjcard.2016.01.012

5. Jabre P, Roger VL, Murad MH, Chamberlain AM, Prokop L, Adnet F, Jouven X: Mortality associated with atrial fibrillation in patients with myocardial infarction: a systematic review and meta-analysis. Circulation. 2011, 123:1587-93. 10.1161/CIRCULATIONAHA.110.986661

6. Goldberg RJ, Yarzebski J, Lessard D, Wu J, Gore JM: Recent trends in the incidence rates of and death rates from atrial fibrillation complicating initial acute myocardial infarction: a community-wide perspective. Am Heart J. 2002, 143:519-27. 10.1067/mhj.2002.120410

7. Rathore SS, Berger AK, Weinfurt KP, Schulman KA, Oetgen WJ, Gersh BJ, Solomon AJ: Acute myocardial infarction complicated by atrial fibrillation in the elderly: prevalence and outcomes. Circulation. 2000, 101:969-74. 10.1161/01.CIR.101.9.969

8. Wong CK, White HD, Wilcox RG, et al.: New atrial fibrillation after acute myocardial infarction independently predicts death: the GUSTO-III experience. Am Heart J. 2000, 140:878-85. 10.1067/mhj.2000.111108

9. Nieuwlaat R, Capucci A, Camm AJ, et al.: Atrial fibrillation management: a prospective survey in ESC member countries: the Euro Heart Survey on Atrial Fibrillation. Eur Heart J. 2005, 26:2422-34. 10.1093/eurheartj/ehi505

10. Fuster V, Rydén LE, Asinger RW, et al.: ACC/AHA/ESC guidelines for the management of patients with atrial fibrillation: executive summary: a report of the American College of Cardiology/American Heart Association Task Force on Practice Guidelines and the European Society of Cardiology Committee for Practice Guidelines and Policy Conferences (Committee to Develop Guidelines for the Management of Patients With Atrial Fibrillation) Developed in collaboration with the North American Society of Pacing and Electrophysiology. J Am Coll Cardiol. 2001, 38:1231-65. 10.1016/S0735-1097(01)01587-X

11. Kirchhof P, Auricchio A, Bax J, et al.: Outcome parameters for trials in atrial fibrillation: executive summary: Recommendations from a consensus conference organized by the German Atrial Fibrillation Competence NETwork (AFNET) and the European Heart Rhythm Association (EHRA). Eur Heart J. 2007, 28:2803-17. 10.1093/eurheartj/ehm358

12. Task Force Members, Lip GY, Windecker S, et al.: Management of antithrombotic therapy in atrial fibrillation patients presenting with acute coronary syndrome and/or undergoing percutaneous coronary or valve interventions: a joint consensus document of the European Society of Cardiology Working Group on Thrombosis, European Heart Rhythm Association (EHRA), European Association of Percutaneous Cardiovascular Interventions (EAPCI) and European Association of Acute Cardiac Care (ACCA) endorsed by the Heart Rhythm Society (HRS) and Asia-Pacific Heart Rhythm Society (APHRS). Eur Heart J. 2014, 35:3155-79.

10.1093/eurheartj/ehu298 
13. Biasco L, Radovanovic D, Moccetti M, et al.: New-onset or pre-existing atrial fibrillation in acute coronary syndromes: two distinct phenomena with a similar prognosis. Rev Esp Cardiol. 2018, 18:1-9. 10.1016/j.rec.2018.03.002

14. Lau DH, Huynh LT, Chew DP, Astley CM, Soman A, Sanders P: Prognostic impact of types of atrial fibrillation in acute coronary syndromes. Am J Cardiol. 2009, 104:1317-23.

10.1016/j.amjcard.2009.06.055

15. Podolecki T, Lenarczyk R, Kowalczyk J, et al.: Effect of type of atrial fibrillation on prognosis in acute myocardial infarction treated invasively. Am J Cardiol. 2012, 109:1689-93.

10.1016/j.amjcard.2012.02.009

16. McManus DD, Huang W, Domakonda KV, Ward J, Saczysnki JS, Gore JM, Goldberg RJ: Trends in atrial fibrillation in patients hospitalized with an acute coronary syndrome. Am J Med. 2012, 125:1076-84. 10.1016/j.amjmed.2012.05.024

17. González-Pacheco H, Eid-Lidt G, Altamirano-Castillo A, et al.: Prevalence and prognostic implications of different types of atrial fibrillation in patients admitted to a coronary care unit. Int J Cardiol. 2014, 172:379-81. 10.1016/j.ijcard.2013.12.291

18. Lopes RD, Elliott LE, White HD, et al.: Antithrombotic therapy and outcomes of patients with atrial fibrillation following primary percutaneous coronary intervention: results from the APEX-AMI trial. Eur Heart J. 2009, 30:2019-28. 10.1093/eurheartj/ehp213

19. Antman EM, Hand M, Armstrong PW, et al.: 2007 Focused Update of the ACC/AHA 2004 Guidelines for the Management of Patients With ST-Elevation Myocardial Infarction: a report of the American College of Cardiology/American Heart Association Task Force on Practice Guidelines: developed in collaboration With the Canadian Cardiovascular Society endorsed by the American Academy of Family Physicians: 2007 Writing Group to Review New Evidence and Update the ACC/AHA 2004 Guidelines for the Management of Patients With ST-Elevation Myocardial Infarction, Writing on Behalf of the 2004 Writing Committee. Circulation. 2008, 117:296-329. 10.1161/CIRCULATIONAHA.107.188209

20. Goldberg RJ, Seeley D, Becker RC, et al.: Impact of atrial fibrillation on the in-hospital and long-term survival of patients with acute myocardial infarction: a community-wide perspective. Am Heart J. 1990, 119:996-1001. 10.1016/S0002-8703(05)80227-3

21. Lehto M, Snapinn S, Dickstein K, Swedberg K, Nieminen MS, OPTIMAAL investigators: Prognostic risk of atrial fibrillation in acute myocardial infarction complicated by left ventricular dysfunction: the OPTIMAAL experience. Eur Heart J. 2004, 26:350-6. 10.1093/eurheartj/ehi064

22. Køber L, Thomsen PE, Møller M, et al.: Effect of dofetilide in patients with recent myocardial infarction and left-ventricular dysfunction: a randomised trial. Lancet. 2000, 356:2052-8. 10.1016/S0140-6736(00)03402-4

23. Pedersen OD, Bagger H, Køber L, Torp-Pedersen C: Trandolapril reduces the incidence of atrial fibrillation after acute myocardial infarction in patients with left ventricular dysfunction. Circulation. 1999, 100:376-80. 10.1161/01.CIR.100.4.376 